\title{
Stimulation of the Prefrontal Cortex Reduces Intentions to Commit Aggression: A Randomized, Double-Blind, Placebo-Controlled, Stratified, Parallel-Group Trial
}

\author{
Colivia Choy, ${ }^{1}$ Adrian Raine, ${ }^{2}$ and Roy H. Hamilton ${ }^{3}$ \\ ${ }^{1}$ Department of Psychology, Nanyang Technological University, Singapore 637332, ${ }^{2}$ Departments of Criminology, Psychiatry, and Psychology, Jerry Lee \\ Center of Criminology, and ${ }^{3}$ Department of Neurology, University of Pennsylvania, Philadelphia, Pennsylvania 19104
}

\begin{abstract}
Although prefrontal brain impairments are one of the best-replicated brain imaging findings in relation to aggression, little is known about the causal role of this brain region. This study tests whether stimulating the dorsolateral prefrontal cortex using transcranial direct current stimulation ( $\mathrm{tDCS}$ ) reduces the likelihood of engaging in aggressive acts, and the mechanism underlying this relationship. In a double-blind, stratified, placebo-controlled, parallel-group, randomized trial, 81 human adults ( 36 males, 45 females) were randomly assigned to an active $(N=39)$ or placebo $(N=42)$ condition, and then followed up $1 \mathrm{~d}$ after the experiment session. Intentions to commit aggressive acts and behavioral aggression were assessed using hypothetical vignettes and a behavioral task, respectively. The secondary outcome was the perception of the moral wrongfulness of the aggressive acts. Compared with the sham controls, participants who received anodal stimulation reported being less likely to commit physical and sexual assault $(p<0.01)$. They also judged aggressive acts as more morally wrong $(p<0.05)$. Perceptions of greater moral wrongfulness regarding the aggressive acts accounted for $31 \%$ of the total effect of tDCS on intentions to commit aggression. Results provide experimental evidence that increasing activity in the prefrontal cortex can reduce intentions to commit aggression and enhance perceptions of the moral wrongfulness of the aggressive acts. Findings shed light on the biological underpinnings of aggression and theoretically have the potential to inform future interventions for aggression and violence.
\end{abstract}

Key words: aggression; moral judgment; prefrontal; transcranial direct current stimulation; violence

Significance Statement

Aggressive behaviors pose significant public health risks. Understanding the etiology of aggression is paramount to violence reduction. Investigations of the neural basis of aggression have largely supported correlational, rather than causal, interpretations, and the mediating processes underlying the prefrontal-aggression relationship remain to be well elucidated. Through a double-blind, stratified, placebo-controlled, parallel-group, randomized trial, this study tested whether upregulation of the prefrontal cortex reduces the likelihood of engaging in aggression. Results provide experimental evidence that increasing prefrontal cortical activity can reduce intent to commit aggressive acts. They also shed light on moral judgment as one mechanism that may link prefrontal deficits to aggression and, in theory, have the potential to inform future approaches toward reducing aggression.

\section{Introduction}

Prefrontal brain impairment is one of the best-replicated risk factors for aggressive behavior. Evidence from neurological research shows that patients with damage to the frontal cortex exhibit more aggressive behavior (Anderson et al., 1999). In addition to head-injury and lesion studies, the imaging and neuropsychological literature

\footnotetext{
Received Nov. 21, 2017; revised March 20, 2018; accepted June 6, 2018.

Author contributions: 0.C., A.R., and R.H.H. edited the paper; 0.C., A.R., and R.H.H. designed research; $0 . C$. performed research; 0 .C. analyzed data; 0 .C. wrote the paper.

The authors declare no competing financial interests.

Correspondence should be addressed to Olivia Choy, Nanyang Technological University, Department of Psychology, 14 Nanyang Drive, Singapore 637332. E-mail: oliviachoy@ntu.edu.sg.

DOI:10.1523/JNEUROSCI.3317-17.2018

Copyright $\odot 2018$ the authors $\quad 0270-6474 / 18 / 386505-08 \$ 15.00 / 0$
}

has documented structural and functional prefrontal deficits in antisocial individuals (Brower and Price, 2001; Yang and Raine, 2009). Findings on the role of the frontal cortex in modulating aggression and violence also extend to sexual offending (Chen et al., 2016).

Within the prefrontal cortex, a meta-analysis of 43 imaging studies found that impairments of the dorsolateral prefrontal cortex (DLPFC) are implicated in antisocial behavior, with a stronger effect for the left $(d=-0.89)$ than right $(d=-0.56)$ DLPFC (Yang and Raine, 2009). This may be due to the DLPFC's broad connection to functions related to aggression, including moral judgment (Mendez, 2009), that can in turn influence the risk of engaging in aggression, a deduction consistent with the neural moral model of antisocial behavior (Raine and Yang, 
2006). More recent findings bolster the meta-analytic evidence. The involvement of the DLPFC in aggressive and antisocial behavior has since been documented in other neuroimaging studies (Dalwani et al., 2011; Fairchild et al., 2013; Alegria et al., 2016). Furthermore, while it has been suggested that DLPFC lesions are associated with apathy and diminished motivation (Levy and Dubois, 2006), a meta-analysis of 126 neuropsychological studies measuring executive functions in antisocial populations documented an effect size of $d=0.44$ for antisocial behavior and $d=$ 0.41 for physical aggression, implicating dorsolateral prefrontal dysfunction in aggression (Ogilvie et al., 2011). It is important to recognize, however, that the DLPFC is not the only prefrontal area implicated in antisocial and aggressive behavior. Other subregions include the ventromedial prefrontal cortex (Hare et al., 2014) and the anterior cingulate cortex (Kolling et al., 2016), areas which have widespread connections to the DLPFC. Together, studies suggest that there is multimethod evidence indicating the possible implication of the DLPFC on antisocial behavior, among other brain regions.

Despite these findings, little is known about the causal role of the prefrontal cortex on aggressive behavior. Conclusions from extant research on the neural foundations of aggression have largely been correlational. Three known studies have tested the effect of prefrontal cortex upregulation on aggression using the Taylor Aggression Paradigm and transcranial direct current stimulation (tDCS), a noninvasive technique that influences neural excitability by delivering a direct, continuous, low-intensity electrical current to cortical areas between anodal and cathodal electrodes (Brunoni et al., 2012). However, findings have been mixed. One study documented that upregulating the right DLPFC reduced proactive aggression in males (Dambacher et al., 2015b), while another revealed that increasing left DLPFC activity resulted in more aggressive behavior when participants were angry (Hortensius et al., 2012). In contrast, upregulation of the inferior frontal cortex did not have a significant effect on aggression (Dambacher et al., 2015a). Whether stimulation targeting the DLPFC can reduce intentions to engage in aggressive acts or behavioral aggression using other measures has not been examined and, to our knowledge, no studies have experimentally investigated the intermediary mechanisms linking prefrontal deficits to aggression.

Given the association between prefrontal impairments and aggression, this study tests the hypothesis that upregulating the prefrontal cortex using tDCS will reduce intent to commit an aggressive act. This study additionally extends the limited literature on tDCS and aggression by using a larger sample. As similarities have been found between the neural mechanisms underlying moral cognition in normal individuals and brain mechanisms impaired in antisocial populations (Raine and Yang, 2006), we also assess whether prefrontal upregulation improves judgments of moral wrongfulness, which may in turn partly account for any effect of prefrontal enhancement on reducing intent to commit aggressive acts.

\section{Materials and Methods}

Trial design. The study consisted of a double-blind, placebo-controlled, stratified, randomized trial comparing a group that received an anodal tDCS intervention with a sham control group. Baseline assessments and one session of tDCS or sham intervention were conducted during the experimental session, while outcome measures were assessed the following day. Tasks and questionnaires were administered in a fixed order. The study was approved by the Institutional Review Board of the University of Pennsylvania and the trial protocol was registered at ClinicalTrials.gov (NCT02427672).

Participants. Eighty-six healthy adults (age, $\geq 18$ years) were recruited in Philadelphia between April 2015 and April 2016. The experiment took place during one visit to the study site. In addition to assessments conducted at baseline, participants were followed up $1 \mathrm{~d}$ after the experimental session using a web-based questionnaire. Exclusion criteria included contraindications to brain stimulation, such as metallic implants near the electrode sites; unstable medical conditions; neurological, cardiovascular, or psychiatric illness; participation in another noninvasive brain stimulation study on the same day; history of adverse reactions to tDCS; and lack of e-mail access. Written informed consent was obtained from all participants.

tDCS intervention. tDCS was administered by trained study personnel using a battery-driven, constant-current stimulator (TCT Research). Two anodal electrodes were placed over the DLPFC bilaterally (F3 and F4) according to the International 10-20 EEG system. A constant current of $2 \mathrm{~mA}$ ( $1 \mathrm{~mA}$ to each DLPFC site) was applied for $20 \mathrm{~min}$ through saline-soaked sponge electrodes $(5 \times 5 \mathrm{~cm})$. A single extracephalic cathodal electrode $(5 \times 7 \mathrm{~cm})$ was placed at the posterior base of the neck to minimize unintentional effects of inhibitory stimulation on brain activity.

Following standard tDCS protocol, stimulation commenced after a $30 \mathrm{~s}$ ramp-up period. The current was ramped down over the last $2 \mathrm{~s}$. The tasks performed during tDCS are understood to influence the behavioral after-effects of stimulation (Gill et al., 2015). Thus, during the stimulation session, all participants performed the Psychology Experiment Building Language (Mueller and Piper, 2014) version of two cognitive tasks known to engage the DLPFC: the Psychomotor Vigilance Task (Dinges and Powell, 1985; Cui et al., 2015), followed by the Iowa Gambling Task (Bechara et al., 1994; Ernst et al., 2002). Although participants in both intervention arms received the same electrode placement and ramp-up/down times, stimulation for the sham control group was discontinued after $30 \mathrm{~s}$. This has proven to be effective for blinding as participants habituate to the sensation of stimulation within seconds of current initiation (Gandiga et al., 2006).

Intentions to commit aggression. Behavioral intentions to commit aggressive acts were assessed using two hypothetical vignettes, which have been studied in samples with characteristics similar to ours (Hannon et al., 2000; Mazerolle et al., 2003). Brief scenarios describing two types of aggression, physical assault and sexual assault, were presented to participants, who responded to the anticipated likelihood that they would commit the aggressive act. Responses were measured on a scale ranging from zero (no chance at all) to 10 (100\% chance).

Perceptions of moral wrongfulness. To assess moral perceptions of the aggressive acts, participants were asked to rate how morally wrong it would be to act as the protagonist in the scenario on a scale from 0 (not at all) to 10 (very). Aggregate measures of aggressive intent and perception of moral wrongfulness were created by combining responses from the physical and sexual assault scenarios (Armstrong and Boutwell, 2012).

Aggression. The voodoo doll task is a reliable and validated behavioral analog measure of aggression (Dewall et al., 2013). In this task, participants were shown a computer-based image of a doll that represented a partner or a close friend. They were told that they were given the opportunity to release their negative energy to that individual by inserting as many pins $(0-51)$ in the doll as they wished. Instructions did not use the word "voodoo." Stabbing the doll with more pins indicated higher levels of aggression.

Randomization and stratification. At the initial visit, participants were randomized into an active stimulation or sham/placebo condition using a computerized urn randomization procedure (Stout et al., 1994). The stratification factors were age (18/19/ $\geq 20$ years), sex (male/female), and ethnicity (Caucasian/non-Caucasian). This stratification was used to balance groups on key demographic variables.

Blinding. Participants and experimenters were blind to the tDCS condition assignment. The trial adhered to established procedures to maintain separation between staff that conducted the stimulation and staff that engaged with the participant. In each experimental session, only one experimenter who set up the tDCS procedure had knowledge of the participant's allocation. To further ensure blinding, all participants were kept blind to the objective of the study and outcome measures were not taken in the presence of research staff as they could lead to biased results. 
In the three cases where double blinding was compromised due to the inability of having $>1$ experimenter at a session, the cases were excluded from analyses. To assess adherence to blinding procedures, James' (James et al., 1996) and Bang's (Bang et al., 2004) blinding indices were calculated using the participants' and blinded experimenters' guesses about group assignment at the end of the experimental session.

Statistical analyses. One-way ANCOVA was used to test group differences in intentions to commit aggression and the behavioral measure of aggression. The following baseline measures were examined as possible covariates: variety of crime throughout the lifetime, aggression, grade point average, trait anxiety, social adversity, psychopathy, the lack of premeditation and sensation-seeking dimensions of impulsivity, and self-control.

In addition to a Self-Report Crime Questionnaire, which asked participants to indicate the number of times they had committed any of 36 criminal and delinquent acts ranging from white-collar and blue-collar offenses (e.g., fraud and shoplifting) to noncriminal, deceptive behaviors (e.g., cheating on an exam), participants' baseline levels of aggression were assessed using the Reactive-Proactive Aggression Questionnaire (Raine et al., 2006). Trait anxiety was assessed using the 20-item Spielberger State-Trait Anxiety Inventory (Spielberger, 1983). A social adversity index was obtained based on responses to 14 items obtained from demographic questionnaires. Items indicating adversity included the following: parent unemployment; mother's low education; father's low education; parental separation or divorce; placement in a foster home, hospital, or other institution during childhood; having $\geq 5$ siblings; born to a teenage mother; a ratio of people per room (including bedrooms, living room, dining room, and kitchen) of $\geq 1.0$; brought up in public housing; parents' use of welfare or food stamps from the government; father or mother had been arrested; father or mother has had problems with alcohol or drugs; father or mother has had physical illness, such as heart or lung problems; father or mother has had mental illness, such as alcoholism, major depression, schizophrenia, or anxiety. To assess psychopathic traits, the short form of the Self-Report of Psychopathy-III questionnaire, comprising 29 items, was administered (Paulhus et al., 2009). Additionally, scores were obtained from the lack of premeditation and sensation-seeking subscales of the short-form version of the UPPS-P Impulsivity Scale [D.R. Lynam, "Development of a Short Form of the UPPS-P Impulsive Behavior Scale (2013), unpublished technical report]. Self-control was assessed using the 13-item Brief Self-Control Scale (Tangney et al., 2004).

Following recommendations, stratification variables and baseline measures associated with the outcomes were adjusted for, while variables with baseline imbalances were not [Committee for Proprietary Medicinal Products (CPMP), 2004; Kahan et al., 2014]. Effect sizes were calculated using partial $\eta$ squared.

To provide information on a mechanism of action accounting for any effect of tDCS on aggressive intent, change in perceptions of moral wrongfulness was examined using ANCOVA. We tested whether enhanced moral judgment mediated group differences in intent to commit aggressive acts via a bootstrapping approach using the PROCESS macro on SPSS statistics software (IBM; Hayes, 2013). Ten thousand bootstrapped samples were drawn from the original data. The indirect effect of $\mathrm{tDCS}$ on intent to commit aggression was calculated as the product of the regression coefficients for the relationship between tDCS and moral judgment and the association between moral judgment and aggressive intent. The percentage mediated, $P_{\mathrm{M}}$, is expressed as the ratio of the indirect to total effect of treatment group on intention to commit aggression (Ditlevsen et al., 2005; Hayes, 2013). Hypothesis tests were two-tailed. Blinding indices were obtained using STATA version 14.0 (Stata). All other statistical analyses were conducted using SPSS version 24.0 (IBM).

\section{Results}

\section{Participant flow and recruitment}

Data were analyzed on a total sample of 81 (Fig. 1). No participants were lost to follow-up. There was no evidence of selection bias as no significant differences were observed between participants who were included in the analyses and those who were not $(p>0.05$; Table 1$)$.

\section{Demographics and adherence to protocol}

Baseline distributions of the hypothesized covariates were generally well balanced between the treatment groups. With the exception of social adversity, demographic variables and baseline characteristics did not differ across groups (Table 2). As the James' blinding indices were $>0.5$ and Bang's blinding indices did not approach 1 or -1 , participants were considered to have been blinded successfully on average (Table 3; James et al., 1996; Bang et al., 2004).

\section{Aggression outcomes}

Prognostic covariates were determined based on bivariate associations between the hypothesized covariates and outcome measures (Table 4). A one-way ANCOVA controlling for self-report crime and baseline aggression levels revealed a main effect of treatment group on aggressive intent, with the active tDCS group reporting a significantly lower likelihood of engaging in aggression compared with the sham control group $\left(F_{(1,70)}=8.40, p<\right.$ $0.01, \eta_{\mathrm{p}}^{2}=0.11$; Fig. $\left.2 A\right)$. There were no significant interaction effects between treatment group and $\operatorname{sex}\left(F_{(1,70)}=0.57, p=0.45\right.$, $\left.\eta_{\mathrm{p}}^{2}=0.01\right)$ and between treatment group and ethnicity $\left(F_{(1,70)}=\right.$ $\left.0.01, p=0.92, \eta_{\mathrm{p}}^{2}<0.001\right)$. Further analyses revealed that intent to commit both physical assault $\left(F_{(1,70)}=5.61, p=0.02, \eta_{\mathrm{p}}^{2}=\right.$ $0.07)$ and sexual assault $\left(F_{(1,70)}=5.64, p=0.02, \eta_{\mathrm{p}}^{2}=0.08\right)$ were lower in the active tDCS group (Fig. $2 A$ ). However, there was no significant group difference in behavioral aggression assessed using the voodoo doll task $\left(F_{(1,71)}=1.31, p=0.26, \eta_{\mathrm{p}}^{2}=0.02\right.$; Fig. 2B). Additional sensitivity analysis conducted on logtransformed and square root-transformed data for the aggression measures yielded substantively similar findings (Fig. 2-1, available at https://doi.org/10.1523/JNEUROSCI.3317-17.2018.f2-1).

\section{Mechanisms accounting for the reduction in intent to commit aggression}

ANCOVA also revealed that compared with controls, the active tDCS group perceived aggressive acts as more morally wrong $\left(F_{(1,71)}=4.64, p=0.04, \eta_{\mathrm{p}}^{2}=0.06\right.$; Fig. $\left.2 C\right)$. In particular, the main effect of treatment group was significant for perceptions of moral wrongfulness regarding sexual assault $\left(F_{(1,71)}=6.81, p=\right.$ $\left.0.01, \eta_{\mathrm{p}}^{2}=0.09\right)$, but not physical assault $\left(F_{(1,71)}=0.96, p=0.33\right.$, $\left.\eta_{\mathrm{p}}^{2}=0.01\right)$. Higher ratings of moral wrongfulness partly mediated the reduction in intention to commit aggressive acts (indirect effect: $b=-0.51 ; 95 \% \mathrm{CI},-1.14$ to $-0.10 ; p<0.05)$. After controlling for perceptions of moral wrongfulness, treatment group was not a significant predictor of aggressive intent (Fig. 3). Moral perception accounted for $31 \%$ of the total effect of treatment group on overall aggressive intent.

Further analysis revealed that moral wrongfulness partly mediated the reduction in likelihood of committing sexual assault (indirect effect: $b=-0.34 ; 95 \% \mathrm{CI},-1.11$ to $-0.03 ; p<0.05$ ), but not physical assault (indirect effect: $b=-0.32 ; 95 \% \mathrm{CI}$, -0.89 to $0.10 ; p>0.05)$. Perceptions of moral wrongfulness accounted for approximately half $\left(P_{\mathrm{M}}=0.56\right)$ of the total effect of treatment group on intent to commit sexual assault. For completeness, sensitivity analyses that included the demographic variables and social adversity as covariates did not substantively change the mediation results (Fig. 3-1, available at https://doi.org/10.1523/JNEUROSCI.3317-17.2018.f3-1).

\section{Adverse events}

tDCS was associated with minimal side effects. No major adverse events were reported over the duration of the study. According to Fertonani et al.'s (2010) scale and consistent with other tDCS 


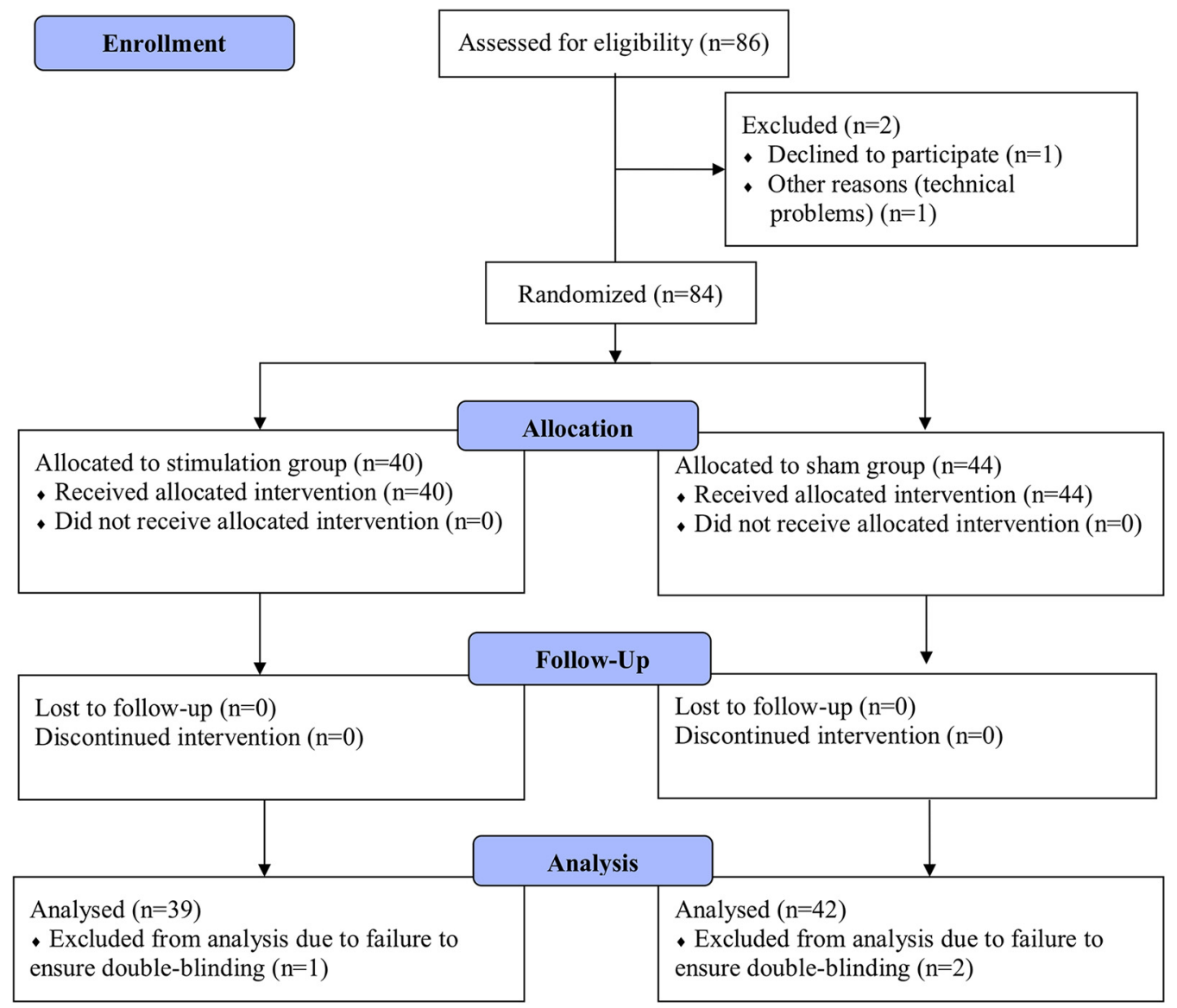

Figure 1. CONSORT (Consolidated Standards of Reporting Trials) flowchart of the screening and enrollment of study participants who were randomly assigned to anodal prefrontal stimulation or a sham control group.

Table 1. Comparison of participants included and excluded in statistical analyses ${ }^{a}$

\begin{tabular}{|c|c|c|c|c|}
\hline Characteristic & $\begin{array}{l}\text { Included } \\
(n=81)\end{array}$ & $\begin{array}{l}\text { Excluded } \\
(n=3)\end{array}$ & Statistic & $p$ value \\
\hline \multicolumn{5}{|l|}{ Demographic variables } \\
\hline \multicolumn{5}{|l|}{ Sex } \\
\hline Female & 45 & 1 & $\chi^{2}=0.58$ & 0.45 \\
\hline Male & 36 & 2 & & \\
\hline Age & $\begin{array}{l}20.21 \text { years } \\
\text { (3.31 years) }\end{array}$ & $\begin{array}{l}20.00 \text { years } \\
(1.73 \text { years })\end{array}$ & $t=0.11$ & 0.91 \\
\hline \multicolumn{5}{|l|}{ Race } \\
\hline Caucasian & 36 & 1 & $\chi^{2}=0.15$ & 0.70 \\
\hline Non-Caucasian & 45 & 2 & & \\
\hline \multicolumn{5}{|l|}{ Baseline measures } \\
\hline$G^{\prime}$ rade point average ${ }^{b}$ & $3.59(0.77)$ & $3.66(0.29)$ & $t=-0.17$ & 0.87 \\
\hline Social adversity & $1.10(1.48)$ & $1.00(1.00)$ & $t=0.11$ & 0.91 \\
\hline Variety of offending & $16.85(6.21)$ & $15.00(5.00)$ & $t=0.51$ & 0.61 \\
\hline Baseline aggression & $9.37(4.72)$ & $10.33(2.08)$ & $t=-0.35$ & 0.73 \\
\hline Psychopathy & $23.17(12.20)$ & $23.00(13.75)$ & $t=0.02$ & 0.98 \\
\hline Lack of premeditation & $1.61(0.49)$ & $1.92(0.14)$ & $t=-1.08$ & 0.28 \\
\hline Sensation-seeking & $2.89(0.64)$ & $2.58(0.52)$ & $t=0.80$ & 0.42 \\
\hline Anxiety & $38.60(8.86)$ & $45.67(13.05)$ & $t=-1.34$ & 0.19 \\
\hline Self-control & $36.26(6.95)$ & $37.00(1.73)$ & $t=-0.18$ & 0.86 \\
\hline \multicolumn{5}{|l|}{ Outcome variables } \\
\hline Aggressive intent & $2.26(3.56)$ & $1.33(0.58)$ & $t=0.45$ & 0.66 \\
\hline $\begin{array}{l}\text { Aggression (voodoo } \\
\text { doll task) }\end{array}$ & $3.91(10.29)$ & $3.33(5.77)$ & $t=0.10$ & 0.92 \\
\hline Moral wrongfulness & $15.20(3.48)$ & $16.33(3.51)$ & $t=-0.56$ & 0.58 \\
\hline
\end{tabular}

${ }^{a}$ Data for continuous variables are presented as mean (SD), with comparisons conducted using independent samples $t$ tests or $\chi^{2}$ tests as appropriate.

${ }^{b}$ For eight individuals whose grade point averages were missing, mean imputation was conducted. Missing values were replaced with the mean of the observed data as suggested in Kahan et al. (2014).
Table 2. Baseline characteristics by treatment arm ${ }^{a}$

\begin{tabular}{|c|c|c|c|c|}
\hline Characteristic & $\begin{array}{l}\text { tDCS group } \\
(n=39)\end{array}$ & $\begin{array}{l}\text { Sham group } \\
(n=42)\end{array}$ & Statistic $^{b}$ & $p$ value \\
\hline \multicolumn{5}{|l|}{ Sex } \\
\hline Female & 24 & 21 & \multirow[t]{2}{*}{$\chi^{2}=1.09$} & \multirow[t]{2}{*}{0.30} \\
\hline Male & 15 & 21 & & \\
\hline Age & $\begin{array}{l}20.26 \text { years } \\
\text { ( } 4.13 \text { years) }\end{array}$ & $\begin{array}{l}20.17 \text { years } \\
(2.36 \text { years })\end{array}$ & $t=-0.12$ & 0.90 \\
\hline \multicolumn{5}{|l|}{ Race } \\
\hline Caucasian & 17 & 19 & \multirow[t]{2}{*}{$\chi^{2}=0.02$} & \multirow[t]{2}{*}{0.88} \\
\hline Non-Caucasian & 22 & 23 & & \\
\hline Grade point average ${ }^{c}$ & $3.55(0.27)$ & $3.47(0.33)$ & $t=-1.18$ & 0.24 \\
\hline Social adversity & $0.72(1.15)$ & $1.45(1.67)$ & $t=2.32$ & 0.02 \\
\hline Variety of offending & $17.36(6.25)$ & $16.38(6.22)$ & $t=-0.71$ & 0.48 \\
\hline Aggression & $9.92(4.97)$ & $8.86(4.48)$ & $t=-1.02$ & 0.31 \\
\hline Psychopathy & $23.33(11.85)$ & $23.02(12.65)$ & $t=-0.11$ & 0.91 \\
\hline Lack of premeditation & $1.59(0.49)$ & $1.63(0.49)$ & $t=0.38$ & 0.71 \\
\hline Sensation-seeking & $2.89(0.65)$ & $2.88(0.65)$ & $t=-0.07$ & 0.94 \\
\hline Anxiety & $38.79(8.53)$ & $38.43(9.25)$ & $t=-0.19$ & 0.85 \\
\hline Self-control & $37.05(6.69)$ & $35.52(7.18)$ & $t=-0.99$ & 0.33 \\
\hline
\end{tabular}

studies (Brunoni et al., 2012), reported side effects included itchiness $(85.2 \%)$, lightheadedness (40.7\%), pain $(46.9 \%)$, burning (49.4\%), warmth (51.2\%), pinching (45.7\%), iron taste (7.4\%), and fatigue of light-to-moderate intensity $(35.0 \%)$. No participants withdrew due to these minor events. 
Table 3. Participant and experimenter conjectures about group assignment and blinding indices

\begin{tabular}{|c|c|c|c|c|c|c|c|}
\hline Intervention & $\mathrm{tDCS}$ & Sham & Do not know & Total & $\begin{array}{l}\text { James' blinding } \\
\text { index }\end{array}$ & $\begin{array}{l}\text { Bang's blinding } \\
\text { index }\end{array}$ & $95 \% \mathrm{Cl}$ \\
\hline \multicolumn{8}{|c|}{ Participant's guess, $n$ (\%) } \\
\hline tDCS & $26(32.1)$ & $3(3.7)$ & $10(12.3)$ & $39(48.1)$ & & 0.59 & $0.42,0.76$ \\
\hline Sham & $18(22.2)$ & $9(11.1)$ & $15(18.5)$ & $42(51.9)$ & & -0.21 & $-0.41,-0.02$ \\
\hline Total & $44(54.3)$ & $12(14.8)$ & $25(30.9)$ & $81(100)$ & 0.57 & & $0.49,0.65$ \\
\hline \multicolumn{8}{|c|}{ Experimenter's guess, $n$ (\%) } \\
\hline tDCS & $12(15.4)$ & $0(0)$ & $25(32.1)$ & $37(47.4)$ & & 0.32 & $0.20,0.45$ \\
\hline Sham & $2(2.6)$ & $2(2.6)$ & $37(47.4)$ & $41(52.6)$ & & 0 & $-0.08,0.08$ \\
\hline Total & $14(17.9)$ & $2(2.6)$ & $62(79.5)$ & $78(100)^{a}$ & 0.84 & & $0.76,0.91$ \\
\hline
\end{tabular}

${ }^{a}$ Due to missing data, three cases were omitted from calculations of the blinding indices.

\begin{tabular}{|c|c|c|c|}
\hline Characteristic & Aggressive intent & Moral wrongfulness & Behavioral aggression \\
\hline $\operatorname{Sex}^{a}$ & $-2.10^{*}$ & $4.21^{* * *}$ & 0.11 \\
\hline $\operatorname{Race}^{b}$ & -0.08 & 0.06 & -0.52 \\
\hline Age & -0.07 & -0.01 & -0.02 \\
\hline Grade point average & 0.13 & 0.02 & 0.15 \\
\hline Social adversity & -0.08 & 0.09 & -0.05 \\
\hline Variety of offending & $0.36^{* *}$ & -0.21 & 0.001 \\
\hline Aggression & $0.42^{* * *}$ & -0.07 & 0.08 \\
\hline Psychopathy & 0.17 & $-0.30^{* *}$ & 0.20 \\
\hline Lack of premeditation & -0.07 & 0.11 & $0.28^{*}$ \\
\hline Sensation-seeking & 0.17 & -0.06 & 0.19 \\
\hline Anxiety & -0.02 & -0.07 & 0.22 \\
\hline Self-control & 0.01 & -0.07 & 0.22 \\
\hline
\end{tabular}

${ }^{a}$ Sex was coded as 0 for female and 1 for male.

${ }^{b}$ Race was coded as 0 for Caucasian and 1 for non-Caucasian.

${ }^{*} p<0.05 ;{ }^{* *} p<0.01$; ${ }^{* * *} p<0.001$.

\section{Discussion}

This study tested a new approach to reducing aggressive and violent behavior. Individuals who underwent bilateral anodal stimulation of the DLPFC using tDCS reported a lower likelihood of committing an aggressive physical and sexual assault $1 \mathrm{~d}$ after stimulation compared with a sham control group. The treatment-aggressive intent relationship was partly accounted for by enhanced perception that the aggressive acts were more morally wrong, resulting from prefrontal upregulation. Findings help to strengthen conclusions from neurological, neuroimaging, and neuropsychological research (Damasio et al., 1994; Damasio, 2000; Yang and Raine, 2009; Liljegren et al., 2015; Rogers and De Brito, 2016) by documenting experimentally the role of the prefrontal cortex on the likelihood of engaging in aggression and the perception of such acts as morally wrong.

Beyond examining experimentally the role of the prefrontal cortex on a behavioral symptom, the finding that moral judgment partly mediates the effect of tDCS on the likelihood of sexual assault contributes to our mechanistic understanding of the etiology of sexual violence. It also provides partial support for the neuro-moral theory of violent behavior, which postulates that violence is due in part to impairments in brain regions subserving moral cognition and emotion (Raine and Yang, 2006). The null mediation effect observed for physical assault suggests that moral judgment plays a greater role on intentions to commit sexual assault, which is consistent with empirical evidence that sexual offenses, such as rape, are rated as more morally wrong than physical violence (Akman et al., 1968; Hsu, 1973). This indicates that moral judgment is likely only one of several processes underlying the prefrontal-aggression relationship.

The difference in our results for behavioral intent and the behavioral measure of aggression warrant attention. Although participants in the tDCS group exhibited significantly lower levels of aggressive intent after the experimental session, they exhibited a nonsignificant increase $(d=0.26)$ in behavioral aggression. These null findings converge with the mixed findings on tDCS and behavioral aggression in the literature to date (Hortensius et al., 2012). Furthermore, a recent case study of two female patients receiving anodal tDCS over the left DLPFC and a cathode over the right DLPFC reported anger attacks after stimulation, although notably, in contrast to the present study, these subjects were diagnosed with major depressive disorder (Hung and Huang, 2017).

Given empirical evidence that changes in intentions precede behavioral change (Webb and Sheeran, 2006), our results indicating lower intent to engage in aggressive acts following anodal prefrontal stimulation suggest that tDCS may be an initial step toward the reduction of aggression. This implication must, however, be tempered with the mixed findings in the extant literature. While the treatment and control groups did not differ on the behavioral measure of aggression, this finding is consistent with the concept that a single session of tDCS may have a limited effect on behavioral change. The longer-lasting therapeutic effects of tDCS are suggested to be associated with repeated, rather than single, sessions of stimulation (Nitsche et al., 2008). Therefore, beyond intent to engage in aggression, future studies need to evaluate whether behavioral changes may be observed with more stimulation sessions.

Several caveats are in order. First, the trial findings are limited to an ostensibly healthy population. As the first study to test the effect of prefrontal cortical upregulation on aggressive intentions, the generalizability of the findings to other samples remains to be seen. A second limitation is that moral judgment and aggressive intent were measured concurrently. Thus, we were unable to confirm the temporal order of the mediator and outcome variable. However, empirical evidence that moral judgments shape behavior (Reynolds and Ceranic, 2007) supports the notion that the mediation model presented reflects the expected temporal effects. Third, this study measured aggressive inclinations $1 \mathrm{~d}$ after the intervention. Further research is needed to determine whether tDCS can produce longer-term reductions in aggressive intent, as well as any reduction in aggressive behavior. Fourth, we were not able in our design to include stimulation of a "control" brain region to help document specificity of findings to the DLPFC. Although it has been documented that the right DLPFC is involved in moral judgment (Tassy et al., 2012), this study did not consider any laterality effects. Fifth, although the findings demonstrate that anodal tDCS resulting in a current flow through the 


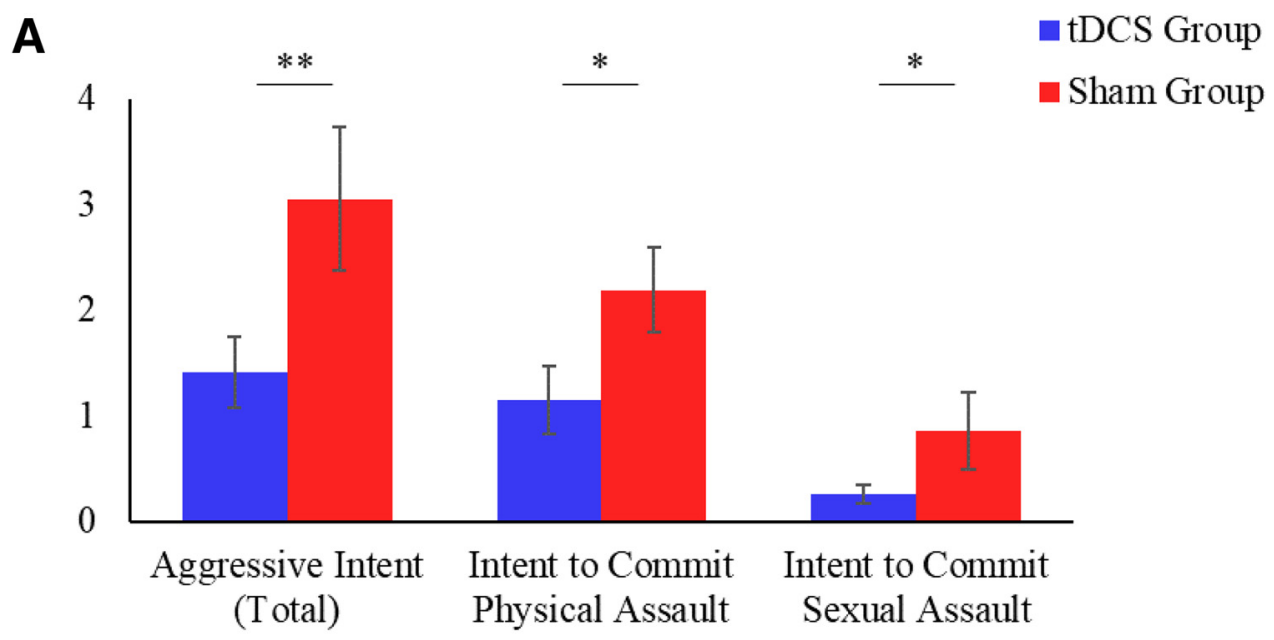

B
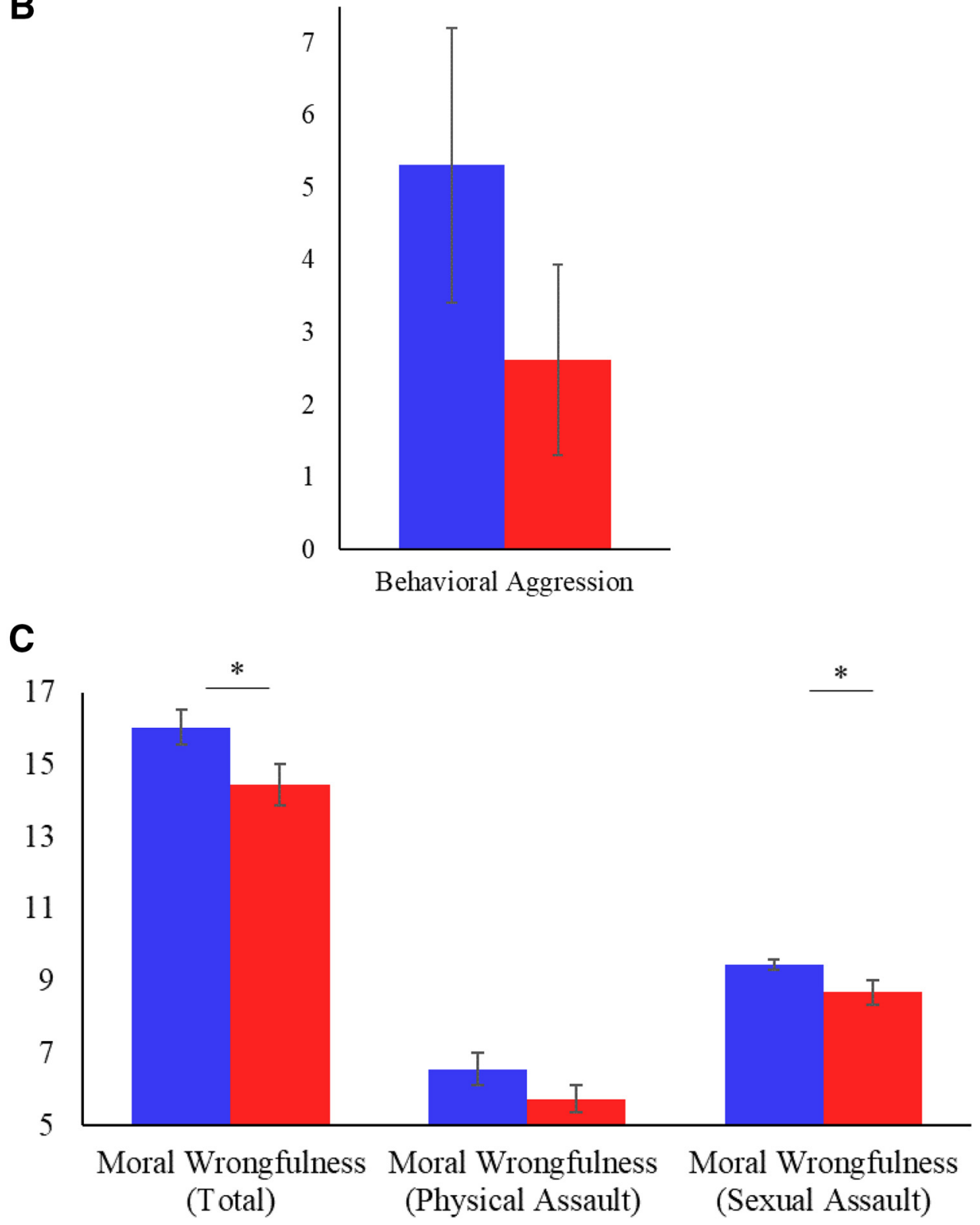

Figure 2. $\boldsymbol{A}-\boldsymbol{C}$, Group means for $(\boldsymbol{A})$ aggressive intent, $(\boldsymbol{B})$ behavioral aggression, and $(\boldsymbol{C})$ perceptions of moral wrongfulness at follow-up. ${ }^{*} p<.05$, ${ }^{* *} p<.01$. Extended data are presented in Figure 2-1, available at https://doi.org/10.1523/JNEUROSCI.3317-17.2018.f2-1. 


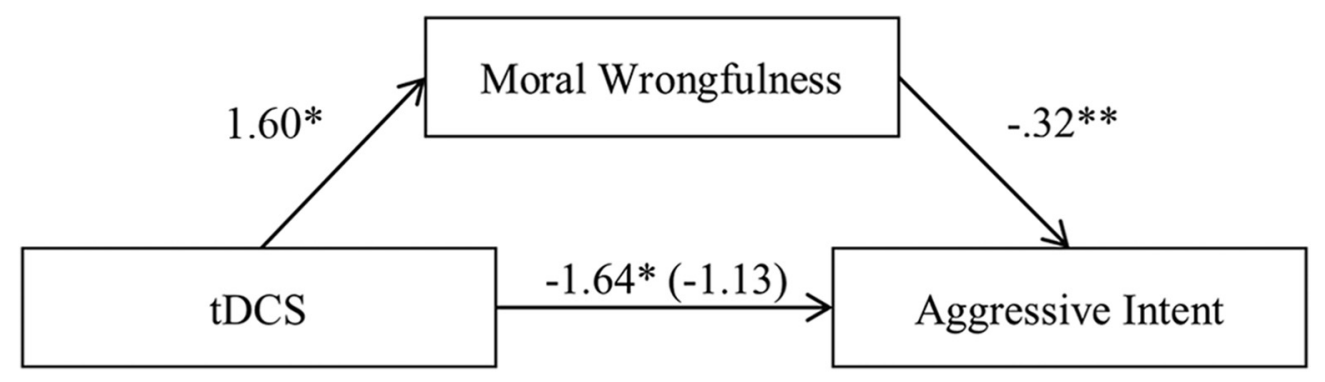

Figure 3. Bootstrapped mediation model documenting that perceptions of greater moral wrongfulness mediated the effect of anodal tDCS on reducing intentions to commit aggression. ${ }^{*} p<$ $.05,{ }^{* *} p<.01$. Extended data are presented in Figure 3-1, available at https://doi.org/10.1523/JNEUROSCI.3317-17.2018.f3-1.

DLPFC influences intentions to commit aggression, they do not negate the involvement of other prefrontal areas, such as the ventromedial and anterior prefrontal cortex, or of nonprefrontal areas, including the temporal cortex. Future studies using complementary noninvasive neurostimulation approaches, such as transcranial magnetic stimulation and high-definition tDCS, may elucidate the anatomical specificity of this effect and the complexity of the functional neuroanatomy of violent behavior.

There has been increasing discussion of biological interventions on antisocial and aggressive behavior in both children and adults (Gesch et al., 2002; Raine et al., 2015; Hübner and White, 2016). Our initial findings, which are limited to intentions to commit aggression and moral judgment, require extensive replication. Nevertheless, among other etiological mechanisms, the role of biological factors on the development of antisocial behavior, including aggression, has been increasingly acknowledged (Raine, 2002; Glenn and Raine, 2014; Latvala et al., 2015). It has been suggested that treatment programs will be improved by considering biological mechanisms that potentially regulate aggression (Beauchaine et al., 2008). Thus, it can be argued that further investigation of basic science trials on tDCS may potentially offer a promising new biological approach for reducing aggression, which is a major public health problem and a feature of a variety of mental disorders, including antisocial personality disorder, intermittent explosive disorder, conduct disorder, and borderline personality disorder (American Psychiatric Association, 2013).

\section{Conclusion}

Understanding the etiology of aggression and the development of new interventions are paramount to a public health approach to violence reduction (Butchart et al., 2004; Slutkin, 2017). This first known application of prefrontal tDCS to study intentions to commit aggression takes a modest step toward advancing knowledge about the neural mechanisms that regulate aggression. Findings provide experimental evidence for the role of the prefrontal cortex on both physical and sexual assault, and suggest how the brain may, in theory, be amenable to change using a noninvasive tool with transient and relatively minor adverse effects (Poreisz et al., 2007; Fertonani et al., 2015). Nevertheless, a stronger evidence base that includes more consistent findings, documentation of long-term beneficial effects, and a comprehensive effort to rule out potentially aversive side effects is required before this technique can be considered in practice to reduce the perpetration of aggressive acts.

\section{References}

Akman D, Normandeau A, Sellin T, Wolfgang M (1968) Towards the measurement of criminality in Canada: a replication study. Acta Criminologica 1:135-260. CrossRef
Alegria AA, Radua J, Rubia K (2016) Meta-analysis of fMRI studies of disruptive behavior disorders. Am J Psychiat 173:1119-1130. CrossRef Medline

American Psychiatric Association (2013) Diagnostic and statistical manual of mental disorders (5th ed.). Washington, DC: American Psychiatric Association.

Anderson SW, Bechara A, Damasio H, Tranel D, Damasio AR (1999) Impairment of social and moral behavior related to early damage in human prefrontal cortex. Nat Neurosci 2:1032-1037. CrossRef Medline

Armstrong TA, Boutwell BB (2012) Low resting heart rate and rational choice: integrating biological correlates of crime in criminological theories. J Crim Jus 40:31-39. CrossRef

Bang H, Ni L, Davis CE (2004) Assessment of blinding in clinical trials. Control Clin Trials 25:143-156. CrossRef Medline

Beauchaine TP, Neuhaus E, Brenner SL, Gatzke-Kopp L (2008) Ten good reasons to consider biological processes in prevention and intervention research. Dev Psychopathol 20:745-774. Medline

Bechara A, Damasio AR, Damasio H, Anderson SW (1994) Insensitivity to future consequences following damage to human prefrontal cortex. Cognition 50:7-15. CrossRef Medline

Brower MC, Price BH (2001) Neuropsychiatry of frontal lobe dysfunction in violent and criminal behaviour: a critical review. J Neurol Neurosurg Psychiatry 71:720-726. CrossRef Medline

Brunoni AR, Nitsche MA, Bolognini N, Bikson M, Wagner T, Merabet L, Edwards DJ, Valero-Cabre A, Rotenberg A, Pascual-Leone A, Ferrucci R, Priori A, Boggio PS, Fregni F (2012) Clinical research with transcranial direct current stimulation (tDCS): challenges and future directions. Brain Stimul 5:175-195. CrossRef Medline

Butchart A, Phinney A, Check P, Villaveces A (2004) Preventing violence: a guide to implementing recommendations of the World Report on Violence and Health. Geneva, Switzerland: Department of Injuries and Violence Prevention, World Health Organization.

Chen CY, Raine A, Chou KH, Chen IY, Hung D, Lin CP (2016) Abnormal white matter integrity in rapists as indicated by diffusion tensor imaging. BMC Neurosci 17:45. CrossRef Medline

Committee for Proprietary Medicinal Products (CPMP) (2004) Committee for Proprietary Medicinal Products (CPMP): points to consider on adjustment for baseline covariates. Statistics in medicine 23:701-709. CrossRef Medline

Cui J, Tkachenko O, Gogel H, Kipman M, Preer LA, Weber M, Divatia SC, Demers LA, Olson EA, Buchholz JL, Bark JS, Rosso IM, Rauch SL, Killgore WD (2015) Microstructure of frontoparietal connections predicts individual resistance to sleep deprivation. Neuroimage 106:123-133. CrossRef Medline

Dalwani M, Sakai JT, Mikulich-Gilbertson SK, Tanabe J, Raymond K, McWilliams SK, Thompson LL, Banich MT, Crowley TJ (2011) Reduced cortical gray matter volume in male adolescents with substance and conduct problems. Drug Alcohol Depend 118:295-305. CrossRef Medline

Damasio AR (2000) A neural basis for sociopathy. Arch Gen Psychiatry 57: 128-129. CrossRef

Damasio H, Grabowski T, Frank R, Galaburda AM, Damasio AR (1994) The return of Phineas Gage: clues about the brain from the skull of a famous patient. Science 264:1102-1105. CrossRef Medline

Dambacher F, Schuhmann T, Lobbestael J, Arntz A, Brugman S, Sack AT (2015a) No effects of bilateral tDCS over inferior frontal gyrus on response inhibition and aggression. PloS One 10:e0132170. CrossRef Medline

Dambacher F, Schuhmann T, Lobbestael J, Arntz A, Brugman S, Sack AT (2015b) Reducing proactive aggression through non-invasive brain stimulation. Soc Cogn Affect Neurosci 10:1303-1309. CrossRef Medline Dewall CN, Finkel EJ, Lambert NM, Slotter EB, Bodenhausen GV, Pond RS Jr, 
Renzetti CM, Fincham FD (2013) The voodoo doll task: introducing and validating a novel method for studying aggressive inclinations. Aggressive Behavior 39:419-439. Medline

Dinges DF, Powell JW (1985) Microcomputer analyses of performance on a portable, simple visual RT task during sustained operations. Behav Res Methods 17:652-655. CrossRef

Ditlevsen S, Christensen U, Lynch J, Damsgaard MT, Keiding N (2005) The mediation proportion: a structural equation approach for estimating the proportion of exposure effect on outcome explained by an intermediate variable. Epidemiology 16:114-120. CrossRef Medline

Ernst M, Bolla K, Mouratidis M, Contoreggi C, Matochik JA, Kurian V, Cadet JL, Kimes AS, London ED (2002) Decision-making in a risk-taking task: a PET study. Neuropsychopharmacology 26:682-691. CrossRef Medline

Fairchild G, Hagan CC, Walsh ND, Passamonti L, Calder AJ, Goodyer IM (2013) Brain structure abnormalities in adolescent girls with conduct disorder. J Child Psychol Psychiatry 54:86-95. CrossRef Medline

Fertonani A, Rosini S, Cotelli M, Rossini PM, Miniussi C (2010) Naming facilitation induced by transcranial direct current stimulation. Behav Brain Res 208:311-318. CrossRef Medline

Fertonani A, Ferrari C, Miniussi C (2015) What do you feel if I apply transcranial electric stimulation? Safety, sensations and secondary induced effects. Clin Neurophysiol 126:2181-2188. CrossRef Medline

Gandiga PC, Hummel FC, Cohen LG (2006) Transcranial DC stimulation (tDCS): a tool for double-blind sham-controlled clinical studies in brain stimulation. Clin Neurophysiol 117:845-850. CrossRef Medline

Gesch CB, Hammond SM, Hampson SE, Eves A, Crowder MJ (2002) Influence of supplementary vitamins, minerals and essential fatty acids on the antisocial behaviour of young adult prisoners. Br J Psychiatry 181:22-28. CrossRef Medline

Gill J, Shah-Basak PP, Hamilton R (2015) It's the thought that counts: examining the task-dependent effects of transcranial direct current stimulation on executive function. Brain Stimul 8:253-259. CrossRef Medline

Glenn AL, Raine A (2014) Neurocriminology: implications for the punishment, prediction and prevention of criminal behaviour. Nat Rev Neurosci 15:54-63. CrossRef Medline

Hannon R, Hall DS, Nash H, Formati J, Hopson T (2000) Judgments regarding sexual aggression as a function of sex of aggressor and victim. Sex Roles 43:311-322. CrossRef

Hare TA, Hakimi S, Rangel A (2014) Activity in dlPFC and its effective connectivity to vmPFC are associated with temporal discounting. Front Neurosci 8:50. CrossRef Medline

Hayes AF (2013) Introduction to mediation, moderation, and conditional process analysis: a regression-based approach. New York, NY: Guilford.

Hortensius R, Schutter DJ, Harmon-Jones E (2012) When anger leads to aggression: induction of relative left frontal cortical activity with transcranial direct current stimulation increases the anger-aggression relationship. Soc Cogn Affect Neurosci 7:342-347. CrossRef Medline

Hsu M (1973) Cultural and sexual differences on the judgment of criminal offenses: a replication study of the measurement of delinquency. J Crim Law Criminol 64:348-353. CrossRef

Hübner D, White L (2016) Neurosurgery for psychopaths? An ethical analysis. AJOB Neurosci 7:140-149. CrossRef

Hung GC, Huang MC (2017) Transient anger attacks associated with bifrontal transcranial direct current stimulation. Brain Stimul 10:981-982. CrossRef Medline

James KE, Bloch DA, Lee KK, Kraemer HC, Fuller RK (1996) An index for assessing blindness in a multi-center clinical trial: disulfiram for alcohol cessation—a VA cooperative study. Stat Med 15:1421-1434. CrossRef Medline

Kahan BC, Jairath V, Doré CJ, Morris TP (2014) The risks and rewards of covariate adjustment in randomized trials: an assessment of 12 outcomes from 8 studies. Trials 15:139. CrossRef Medline

Kolling N, Wittmann MK, Behrens TE, Boorman ED, Mars RB, Rushworth MF (2016) Value, search, persistence and model updating in anterior cingulate cortex. Nat Neurosci 19:1280-1285. CrossRef Medline

Latvala A, Kuja-Halkola R, Almqvist C, Larsson H, Lichtenstein P (2015) A longitudinal study of resting heart rate and violent criminality in more than 700000 men. JAMA Psychiatry 72:971-978. CrossRef Medline

Levy R, Dubois B (2006) Apathy and the functional anatomy of the prefrontal cortex-basal ganglia circuits. Cereb Cortex 16:916-928. CrossRef Medline

Liljegren M, Naasan G, Temlett J, Perry DC, Rankin KP, Merrilees J, Grinberg LT, Seeley WW, Englund E, Miller BL (2015) Criminal behavior in frontotemporal dementia and alzheimer disease. JAMA Neurol 72:295-300. CrossRef Medline

Mazerolle P, Piquero AR, Capowich GE (2003) Examining the links between strain, situational and dispositional anger, and crime: further specifying and testing general strain theory. Youth Soc 35:131-157. CrossRef

Mendez MF (2009) The neurobiology of moral behavior: review and neuropsychiatric implications. CNS Spectr 14:608-620. CrossRef Medline

Mueller ST, Piper BJ (2014) The psychology experiment building language (PEBL) and PEBL test battery. J Neurosci Methods 222:250-259. CrossRef Medline

Nitsche MA, Cohen LG, Wassermann EM, Priori A, Lang N, Antal A, Paulus W, Hummel F, Boggio PS, Fregni F, Pascual-Leone A (2008) Transcranial direct current stimulation: state of the art 2008. Brain Stimul 1:206223. CrossRef Medline

Ogilvie JM, Stewart AL, Chan RC, Shum DH (2011) Neuropsychological measures of executive function and antisocial behavior: a meta-analysis. Criminology 49:1063-1107. CrossRef

Paulhus DL, Neumann CS, Hare RD (2009) Manual for the self-report psychopathy scale. Toronto, Canada: Multi-Health Systems.

Poreisz C, Boros K, Antal A, Paulus W (2007) Safety aspects of transcranial direct current stimulation concerning healthy subjects and patients. Brain Res Bull 72:208-214. CrossRef Medline

Raine A (2002) Biosocial studies of antisocial and violent behavior in children and adults: a review. J Abnorm Child Psychol 30:311-326. CrossRef Medline

Raine A, Yang Y (2006) Neural foundations to moral reasoning and antisocial behavior. Soc Cogn Affect Neurosci 1:203-213. CrossRef Medline

Raine A, Dodge K, Loeber R, Gatzke-Kopp L, Lynam D, Reynolds C, Stouthamer-Loeber M, Liu J (2006) The reactive-proactive aggression questionnaire: differential correlates of reactive and proactive aggression in adolescent boys. Aggress Behav 32:159-171. CrossRef Medline

Raine A, Portnoy J, Liu J, Mahoomed T, Hibbeln JR (2015) Reduction in behavior problems with omega-3 supplementation in children aged 8-16 years: a randomized, double-blind, placebo-controlled, stratified, parallelgroup trial. J Child Psychol Psychiatry 56:509-520. CrossRef Medline

Reynolds SJ, Ceranic TL (2007) The effects of moral judgment and moral identity on moral behavior: an empirical examination of the moral individual. J Appl Psychol 92:1610-1624. CrossRef Medline

Rogers JC, De Brito SA (2016) Cortical and subcortical gray matter volume in youths with conduct problems: a meta-analysis. JAMA Psychiatry 73: 64-72. CrossRef Medline

Slutkin G (2017) Reducing violence as the next great public health achievement. Nat Hum Behav 1:0025. CrossRef

Spielberger CD (1983) Manual for the State-Trait Anxiety Inventory STAI (Form Y). Palo Alto, CA: Consulting Psychologists.

Stout RL, Wirtz PW, Carbonari JP, Del Boca FK (1994) Ensuring balanced distribution of prognostic factors in treatment outcome research. J Stud Alcohol Suppl 12:70-75. Medline

Tangney JP, Baumeister RF, Boone AL (2004) High self-control predicts good adjustment, less pathology, better grades, and interpersonal success. J Pers 72:271-324. CrossRef Medline

Tassy S, Oullier O, Duclos Y, Coulon O, Mancini J, Deruelle C, Wicker B (2012) Disrupting the right prefrontal cortex alters moral judgment. Social Cognitive and Affective Neuroscience 7: 282-288. CrossRef Medline

Webb TL, Sheeran P (2006) Does changing behavioral intentions engender behavior change? A meta-analysis of the experimental evidence. Psychol Bull 132:249-268. CrossRef Medline

Yang Y, Raine A (2009) Prefrontal structural and functional brain imaging findings in antisocial, violent, and psychopathic individuals: a metaanalysis. Psychiatry Res 174:81-88. CrossRef Medline 